\title{
Oxidative Decarboxylation of Dicarboxylic Acid by Pyridiniumdichromate- Kinetic and Mechanistic Study
}

\author{
RAKESH KUMAR SHARMA ${ }^{1}$, DASHRATH SINGH RATHORE ${ }^{1}$ \\ and B. K. DANGARH ${ }^{2}$ \\ ${ }^{1}$ Department of Chemistry, Pacific University, Udaipur, India \\ ${ }^{2}$ Department of Chemistry, Govt. P. G. College, Neemuch, India \\ bkdangarh11@gmail.com
}

Received 22 February 2015 / Accepted 4 March 2015

\begin{abstract}
Oxidation of dicarboxylic acid viz-oxalic acid by pyridiniumdichromate (PDC) in perchloric acid medium has been studied. Active oxidizing species involved is protonated PDC. First order plot is observed for $\log (\mathrm{a}-\mathrm{x})$ versus time. Effect of concentration of $\mathrm{PDC}, \mathrm{HClO}_{4}, \mathrm{Mn}$ (II), $\mathrm{Ce}(\mathrm{III})$ and ionic strength has been investigated. Thermodynamic parameters have been evaluated. Energy of activation is $51.22 \mathrm{~kJ} \mathrm{~mol}^{-1}$. Entropy of activation is low and negative. The activation energy does not correspond to $\mathrm{C}-\mathrm{C}$ bond breaking, but the reaction products indicate $\mathrm{C}-\mathrm{C}$ bond breaking. A cyclic complex formation, which undergoes $\mathrm{C}-\mathrm{C}$ fission, has been suggested.
\end{abstract}

Keywords: Oxalic acid, Pyridiniumdichromate, Oxidation, Kinetics

\section{Introduction}

Studies of oxidation processes have many fold advantages not only in living system but also in analytical, commercial, synthetic and industrial fields. PDC is a mild and selective oxidizing agent and soluble in water and many organic solvents. Kumbhat ${ }^{1}$ et al. oxidizes formic and oxalic acid by QBC in DMSO and reported that the main product was carbon dioxide. The reaction was first order with respect with respect to QBC. Mohanty et al. ${ }^{2}$ studied the oxidation of oxalate and glyoxylate by iodine in the temperature range of $70^{\circ}-$ $80{ }^{\circ} \mathrm{C}$ and reported that change in ionic strength have no effect on reaction rate; while decrease in rate is observed with decrease in $\mathrm{pH}$. The author confirmed that protonated form of oxalate and glyoxylate have lower reactivities. In this paper we propose to investigate the mechanism of oxidation by pyridiniumdichromate (PDC) and to check the reactivity towards PDC, we have selected oxalic acid as the substrate.

\section{Experimental}

All solutions were prepared in double distilled water. Pre-determined volume of known concentration of oxalic acid, perchloric acid and water were mixed in a glass stoppered flask kept in a thermostat at constant temperature $(308 \pm 0.1 \mathrm{~K})$. Reaction was initiated by adding 
pyridiniumdichromate solution. Aliquots $(2.0 \mathrm{~mL})$ were withdrawn at known intervals of time and concentration of the oxidant was determined iodometrically. All chemicals used were AR grade or were purified before use. Purity was checked by m.p. and b. p.

\section{Results and Discussion}

\section{Effect of oxidant concentration}

The PDC concentration was varied in the range $1 \times 10^{-3}$ to $3 \times 10^{-3} \mathrm{~mol} \mathrm{dm}^{-3}$ and the linearity of plots of $\log [\mathrm{PDC}] v s$. time indicated a reaction order in [PDC] as unity. This was also confirmed by varying the [PDC], which did not show any change in pseudo-first order rate constants $\mathrm{k}_{\mathrm{obs}}$ (Table 1). The first order plot is straight line.

Table 1. Effect of [Oxalic acid] and [PDC] on the oxidation of Oxalic acid by PDC $\left[\mathrm{HClO}_{4}\right]=5.0 \times 10^{-1} \mathrm{~mol} \mathrm{dm}^{-3} \mathrm{Temp}=308 \mathrm{~K}$

\begin{tabular}{ccc}
\hline $10^{2}$ [Oxalic acid] $\mathrm{mol} \mathrm{dm}^{-3}$ & $10^{3}[\mathrm{PDC}] \mathrm{mol} \mathrm{dm}^{-3}$ & $10^{5} \mathrm{k}_{\mathrm{obs}} \mathrm{s}^{-1}$ \\
\hline 2.0 & 2.0 & 13.76 \\
2.5 & 2.0 & 19.73 \\
3.0 & 2.0 & 26.97 \\
3.5 & 2.0 & 38.64 \\
4.0 & 2.0 & 46.37 \\
4.5 & 2.0 & 56.92 \\
5.0 & 2.0 & 69.31 \\
2.0 & 1.0 & 13.68 \\
2.0 & 1.25 & 13.87 \\
2.0 & 1.5 & 13.50 \\
2.0 & 1.75 & 14.10 \\
2.0 & 2.0 & 13.76 \\
2.0 & 2.5 & 14.18 \\
2.0 & 3.0 & 13.92 \\
\hline
\end{tabular}

\section{Effect of substrate concentration}

The substrate, [oxalic acid] was varied in the range $2.0 \times 10^{-2}$ to $5.0 \times 10^{-2} \mathrm{~mol} \mathrm{dm}^{-3}$ at $308 \mathrm{~K}$ keeping all other reactant concentration and conditions constant. Rate of oxidation of oxalic acid increases with increasing substrate concentration. (Table 1). Log $\mathrm{k}$ versus $\log$ [substrate] is a straight line with slope 1.8. This observation is similar to oxidation of oxalic acid by chromic acid ${ }^{3}$.

\section{Effect of initially added products}

The effect of initially added products such as pyridine in the concentration range $2.0 \times 10^{-2}$ to $2.0 \times 10^{-1} \mathrm{~mol} \mathrm{dm}^{-3}$ keeping all other conditions constant did not show any significant effect on the rate of reaction. It shows that there is no hydrolysis of PDC in kinetic condition and hence oxidant is quite stable in kinetic condition.

\section{Effect of varying acidity}

The effect of acid on the reaction was studied by using perchloric acid at constant concentration of oxalic acid and PDC. The rate of oxidation was studied from $\left[\mathrm{H}^{+}\right]=0.0 \mathrm{M}$ to $1.6 \mathrm{M}$. It was observed that rate increases with increase in hydrogen ion concentration (Table 2). Log $\mathrm{k}$ versus $\log \left[\mathrm{H}^{+}\right]$is a straight line and order with respect to hydrogen ion is 0.3 , which is an exception. This is contrary to observation of Kumbhat ${ }^{1}$ and Banerji ${ }^{4}$, where the order is one with respect to hydrogen ion concentration. The plot of $\mathrm{k} v s .\left[\mathrm{H}^{+}\right]$are linear 
and intercept at y-axis is nearly zero. It confirms that the reaction is acid catalyzed. Since protonation of the acid is not possible, therefore, it can be concluded that protonated oxidant is active species in this oxidation.

Table 2. Effect of $\left[\mathrm{H}^{+}\right]$ion $^{\mathrm{a}}$

\begin{tabular}{cc}
\hline $10 \times\left[\mathrm{HClO}_{4}\right] \mathrm{mol} \mathrm{dm}^{-3}$ & $10^{5} \mathrm{k}_{\mathrm{obs}} \mathrm{s}^{-1}$ \\
\hline 1.0 & 9.03 \\
3.0 & 10.93 \\
4.0 & 12.15 \\
5.0 & 13.39 \\
6.0 & 13.76 \\
7.0 & 14.71 \\
8.0 & 15.41 \\
9.0 & 16.31 \\
10.0 & 17.28 \\
11.0 & 18.06 \\
12.0 & 19.10 \\
\hline Oxalic acid $]=2 \times 10-2 \mathrm{~mol} \mathrm{dm}^{-3}[\mathrm{PDC}]=2.0 \times 10-3 \mathrm{~mol} \mathrm{dm}^{-3} \mathrm{Temp}=308 \mathrm{~K}$
\end{tabular}

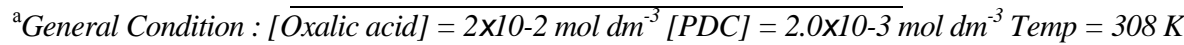

\section{Effect of solvent polarity}

Effect of solvent polarity was studied (Table 3) by changing proportion of water and 1,4 dioxane; percentage composition was varied from 0 to $10 \%$ dioxane $\mathrm{v} / \mathrm{v}$. Since there is no literature value of water-dioxane solution of different composition, therefore we have calculated dielectric constant using law of mixture and data for pure dioxane and water, ${ }^{6,7}$ assuming a linear relationship in the limited range 0 to $30 \%$ of solvent compositions used in our studies. Wieberg and Evans ${ }^{8}$ have made a similar approximation with regard to the same binary solvent system. Looking to the nature of reaction, it can be either ion-dipole or dipoledipole ${ }^{9}$. Many workers like Jain ${ }^{10}$, and Hiran et al. ${ }^{11}$ suggested ion-dipole type of interaction in the oxidation of organic substrates by $\mathrm{Cr}(\mathrm{VI})$-complexes. Although the dielectric constants of the medium by itself is inadequate to account for the solvent influence ${ }^{12}$, the relative solvation and greater electrostatic attraction of solute for the more polar compounds of mixed solvent may produce a field of dielectric constant near the solute particle, which is entirely different from the average dielectric constants. Solvent-solute interaction therefore may be more important factor in affecting the reaction rate compared to the dielectric constants ${ }^{13}$.

It was observed that $\log \mathrm{k}$ versus 1 /dielectric constant is straight line with the positive slope. This indicates that reaction is ion-dipolar and further by positive slope, we can say it is cation-dipole interaction in rate determining step ${ }^{14}$.

Effect of temperature

Rate of reactions were determined at different temperature (298 to $323 \mathrm{~K}$ ). A plot of $\log \mathrm{k}_{\mathrm{obs}}$ versus $1 / \mathrm{T}$ (inverse of absolute temperature) is a straight line (Table 4). Energy of activation is $51.22 \mathrm{~kJ} \mathrm{~mol}^{-1}$. Entropy of activation is low and negative.

Energy of activation does not correspond to carbon-carbon bond fission in the decomposition of organic substrate by $\mathrm{Cr}(\mathrm{VI})$ in rate determining step ${ }^{15}$. But the reaction product indicate $\mathrm{C}-\mathrm{C}$ bond breaking. This may be due to lowering of activation energy $\left(\Delta \mathrm{E}^{\#}\right.$ $=51.22 \mathrm{~kJ} \mathrm{~mol}^{-1}$ ) due to involvement of many equilibria. Decrease in entropy suggests formation of cyclic complex (may be unstable). Calculation of activation parameters showed that this reaction is not enthalpy controlled. 
Table 3. Effect of solvent ${ }^{\mathrm{a}}$

\begin{tabular}{cc}
\hline Dioxane $\% \mathrm{v} / \mathrm{v}$ & $10^{5} \mathrm{k}_{\mathrm{obs}} \mathrm{s}^{-1}$ \\
\hline 0.0 & 13.76 \\
5.0 & 19.03 \\
10.0 & 25.07 \\
15.0 & 29.18 \\
50.0 & 32.34 \\
25.0 & 37.12 \\
30.0 & 41.96 \\
\hline
\end{tabular}

Table 4. Effect of temperature ${ }^{\mathrm{a}}$

\begin{tabular}{cc}
\hline Temp K & $10^{5} \mathrm{k}_{\text {obs }} \mathrm{s}^{-1}$ \\
\hline 298 & 6.51 \\
303 & 9.82 \\
308 & 13.76 \\
313 & 18.26 \\
318 & 25.64 \\
323 & 35.82 \\
328 & 46.12 \\
333 & 57.62 \\
\hline
\end{tabular}

${ }^{\mathrm{a}}$ General Condition : [Oxalic acid] $=2.0 \times 10^{-2} \mathrm{~mol} \mathrm{dm}-3[\mathrm{PDC}]=2.0 \times 10^{-3} \mathrm{~mol} \mathrm{dm}^{-3}\left[\mathrm{HClO}_{4}\right]=5 \times 10^{-1} \mathrm{~mol} \mathrm{dm}^{-3}$

Variation of rate with $\mathrm{Mn}(\mathrm{II})$ ion

It was observed that an addition of $\mathrm{Mn}(\mathrm{II})$ ion retard the rate of oxidation with increase in concentration of $\mathrm{Mn}(\mathrm{II})$ ion.(Table 5). Such observations were also reported by Hiran et.al ${ }^{16}$, The retardation of the reaction rate can be explained by disproportionation of $\mathrm{Cr}(\mathrm{VI})$ to $\mathrm{Cr}(\mathrm{V})$ and $\mathrm{Cr}(\mathrm{III})$, catalyzed by $\mathrm{Mn}(\mathrm{II})$. Thangarajan and Gopalan ${ }^{14}$ also observed similar effect of $\mathrm{Mn}(\mathrm{II})$ and $\mathrm{Ce}$ (III) ions in oxidation of 2-propanol by chromic acid in dioxane-water system. Nalwaya ${ }^{11}$ also observed similar results in oxidation of aromatic aldehydes and alcohol by QBC in dioxane-water medium. This confirms that PDC act as two-electron oxidant in the oxidation of oxalic acid ${ }^{17}$.

Table 5. Effect of $\mathrm{Mn}(\mathrm{II})^{\mathrm{a}}$

\begin{tabular}{cc}
\hline $10^{3}[\mathrm{Mn}(\mathrm{II})] \mathrm{mol} \mathrm{dm}^{-3}$ & $10^{5} \mathrm{k}_{\mathrm{obs}} \mathrm{s}^{-1}$ \\
\hline 0.0 & 13.76 \\
2.0 & 10.84 \\
4.0 & 7.92 \\
6.0 & 5.39 \\
8.0 & 3.86 \\
10.0 & 2.92
\end{tabular}

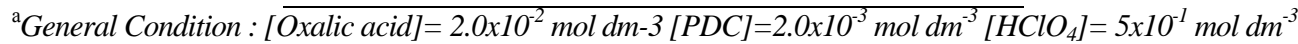

\section{Conclusion}

Rate of oxidation of oxalic acid increases with increase in substrate concentration. Log $\mathrm{k}_{1}$ versus $\log$ [substrate] is a straight line with slope $=1.8$. This observation is similar to oxidation of oxalic acid by chromic acid ${ }^{18}$.

$$
\begin{gathered}
\mathrm{PDC}+\mathrm{H}^{+} \rightleftharpoons[\mathrm{HPDC}]^{+} \\
\mathrm{HPDC}+2 \text { Oxalic acid } \rightleftharpoons \text { Complex }
\end{gathered}
$$

Both $\mathrm{Cr}(\mathrm{VI})$ of PDC combined with oxalic acid and can form compound like (Figure 1).

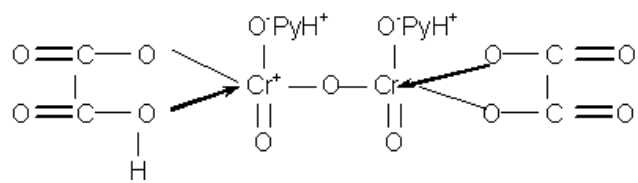

Figure 1. A ternary complex with oxalic acid

\section{References}

1. Kumbhat R, Sharma V and Banerji K K, J Indian Chem Soc., 2003, 80 (9), 815. 
2. Dash S S, (Mrs.) Mohapatra N, Panda B P and Mohanty N K, Indian J Chem., 1990, 29A, 592.

3. Wieberg K B, Chapter 2 of Oxidation in Organic Chemistry part A, Academic Press, New- York, 1965, 69-70.

4. Asopa R, Mathur P and Banerji K K, J Chem Res., 1992,152, 1117

5. Grunwald E, Heller A and Klein F S, J Chem Soc., 1957, 2604-2613; DOI:10.1039/JR9570002604

6. Zimmermans H E, Physicochemical Constants of Pure Organic Comp. Elsevir, 1950, 383.

7. Raymond J W Fevre Le, Trans Faraday Soc., 1938, 34, 1127-1132; DOI:10.1039/TF9383401127

8. Wieberg K B and Evans T R, J Am Chem Soc., 1958, 80, 3019-3022; DOI:10.1021/ja01545a031

9. Laidler K J and Eyring H, Acad Sci New York, 1940, 39, 303.

10. Hiran B L, Jain R and Nalwaya N, Oxidn Commun., 2003, 26(4), 561.

11. Nalaya N, Chand K and Hiran B L, Afinidad., 2003, 60(503. 55- 60.

12. Hiran B L and Chaturvedi G, Oxid Commun., 2003, 26(4), 553.

13. Robinson R A and Stokes R H, "Electrolytic Solutions "Butterworth Scientific Publications, London, 1955.

14. Thangarajan A and Gopalan R, J Indian Chem Soc., 1990, 67, 453.

15. Bakore G V and Narain S, Z Physik Chem (Leipzig), 1964, 8, 227.

16. Hiran B L, Nalwaya N and Bikaneria S.L, Afinidad, 2003, 60(505), 277-281.

17. Dangarh B K, Hiran B L and Joshi S N, Oxid Commun., 2012, 35(2), 352-361

18. Wieberg K B, Chapter 2 of Oxidation in Organic Chemistry part A, Academic Press, New-York, 1965, 69-70. 